\title{
Validação da Versão Brasileira do Check List para Avaliação da Personalidade (PACL) ${ }^{1}$
}

\author{
Ricardo Primi ${ }^{2}$ \\ Lucas de Francisco Carvalho \\ Aracele Netto Gonçalves Braido \\ Carlos Henrique Sancineto Nunes \\ Universidade São Francisco
}

\begin{abstract}
RESUMO - O presente estudo teve como objetivos: (1) produzir uma versão brasileira do Personality Adjective Check List (PACL), um instrumento para avaliação da personalidade baseado nos estilos saudáveis e patológicos de personalidade propostos por Millon, (2) verificar evidências de validade do instrumento por meio da análise fatorial dos itens (estrutura interna) e por meio da relação com variáveis externas, e (3) investigar a consistência interna do instrumento. Foram participantes 203 universitários, entre 18 e 50 anos de idade, sendo 98 homens e 105 mulheres. Foram encontrados cinco fatores que corroboraram pesquisas anteriores com o PACL. Os coeficientes de fidedignidade dos fatores originais variaram de 0,66 a 0,95 . Os resultados sugerem que o PACL possui propriedades psicométricas adequadas.
\end{abstract}

Palavras-chave: avaliação da personalidade; transtornos da personalidade; validação de escala.

\section{Brazilian Version of the Personality Assessment Check List (PACL) Validation}

\begin{abstract}
This paper aimed: (1) to produce a Brazilian version of the Personality Adjective Check List (PACL), a test for personality assessment based on normal version styles proposed by Millon's personality disorders theory, (2) to verify validity evidence of the instrument by means of a factorial analysis (internal structure) and of the relationship with external variables, and (3) to investigate internal consistency of the scales. Participants were 203 undergraduate students, aged from 18 to 50 years old, 98 men and 105 women. It was found five factors in accordance with previous research on PACL. The reliability coefficients of the original factors ranged from 0,66 to 0,95 . The results suggest that the PACL has adequate psychometric properties.
\end{abstract}

Keywords: personality assessment; personality disorders; scale validity.

É comum que clínicos e pesquisadores sejam treinados para procurar por patologias em seus pacientes, contudo, não necessariamente são treinados para investigar os aspectos saudáveis desses pacientes. Atualmente, avanços recentes nas teorias de saúde mental, especialmente no que se refere ao tratamento, têm oferecido grande suporte para os profissionais na estruturação de planejamento para além da psicopatologia (Strack, 2005).

Tais mudanças no paradigma da saúde mental podem ser visualizadas em teorias da personalidade que consideram os aspectos saudáveis e patológicos do funcionamento como pontos distintos de um mesmo continuum. A teoria da personalidade de Theodore Millon (Millon \& Davis, 1996; Strack, 1987) propõe que estilos saudáveis e estilos patológicos da personalidade se relacionam e se distinguem, e, portanto, se encontram em diferentes pontos, mas de um mesmo continuum, e não em categorias diferentes. O que justifica e fundamenta essa proposta teórica é que ambos os modelos de

1 As atividades de pesquisa do primeiro autor que deram origem a este artigo foram financiadas pelo CNPq e pela FAPESP.

2 Endereço para correspondência: Universidade São Francisco, Laboratório de Avaliação Psicológica e Educacional (labape), Mestrado em Psicologia. Rua Alexandre Rodrigues Barbosa, 45. Itatiba, SP. CEP 13251-900. Fone (0XX11) 45348118.E-mail: ricardo.primi@ saofrancisco.edu.br ou rprimi@uol.com.br. personalidade, patológico e saudável, emergem das mesmas fontes e variáveis (Davis, 1999; Millon \& Davis, 1996).

A teoria de Millon (Millon \& Davis, 1996) propõe três eixos - prazer/dor, ativo/passivo e outro/eu - como base das personalidades saudável e patológica. Os estilos da personalidade, compreendidos em termos de modos de enfrentamento designados a maximizar reforçamentos e evitar punições, emergem a partir do eixo ativo-passivo com quatro estratégias de reforçamento - desprendido, dependente, independente e ambivalente. Assim, são derivados oito estilos básicos da personalidade (Introvertido, Inibido, Cooperativo, Sociável, Confiante, Enérgico, Respeitoso e Sensível) e três variantes severos (Esquizotípico, Borderline e Paranóide) (Guevara \& Strack, 1998). Os estilos básicos podem se desenvolver em funcionamentos saudáveis ou patológicos da personalidade, enquanto os três estilos mais severos somente em manifestações mais desadaptativas, que estão mais relacionadas com o espectro patológico da personalidade (Strack, 2005).

Millon descreveu os estilos da personalidade na forma de protótipos, ou seja, dando retratos de como indivíduos com características particularmente salientes podem parecer para um clínico ou outro observador (Strack, 2005). Ainda que não exista uma linha divisória entre o que é saudável e o que é patológico para a personalidade, os estilos saudáveis podem ser distinguidos dos estilos patológicos principalmente por 
apresentarem uma flexibilidade adaptativa frente às demandas do cotidiano (Millon \& Davis, 1996). Para avaliação dos estilos saudáveis da personalidade, segundo o modelo teórico integrativo de Millon, Strack (1987) desenvolveu e validou um instrumento no formato de lista de adjetivos - $\mathrm{o}$ Personality Adjective Check List (PACL).

\section{Desenvolvimento do PACL}

O PACL foi desenvolvido inicialmente com o objetivo de mensurar os oito estilos básicos da personalidade propostos por Millon - Introvertido, Inibido, Cooperativo, Sociável, Confiante, Enérgico, Respeitoso e Sensível - e também três tipos mais severos da personalidade - Esquizotípica, Borderline e Paranóide. Segundo Strack (1987), a escolha por desenvolver um instrumento em formato de check list é baseada na facilidade para administração desse tipo de instrumento, tanto na aplicação quanto na correção (ver também Strack \& Lorr, 1990).

Em seu desenvolvimento, o instrumento era composto por 600 itens desenvolvidos por doutores e estudantes de graduação de psicologia que utilizaram diversas fontes (científicas e dicionários) para a elaboração dos itens. Ao longo do processo, itens redundantes, difíceis, ambíguos ou obscuros foram eliminados, de modo que sete profissionais e estudantes de psicologia foram convidados a completar o instrumento. Nessa etapa, 405 itens (adjetivos) foram mantidos (Strack, 1987).

$\mathrm{O}$ instrumento com 405 itens, distribuídos em 11 diferentes escalas (oito estilos básicos mais três estilos severos da personalidade), foi aplicado em uma amostra composta por 459 adultos entre 16 e 50 anos de idade, e era esperado que estes itens apresentassem consistência interna, estabilidade temporal, sobreposição teoricamente hipotetizada de itens (item overlap) e intercorrelação entre escalas. Durante esse estágio de desenvolvimento do PACL, observou-se que grande parte dos itens que mensuravam as três personalidades mais severas não atendia aos critérios mínimos para que fossem mantidos. Assim, foram mantidos apenas 11 itens dessas três escalas, que representam a Escala Indicadora de Problema.

A partir do instrumento obtido, itens das oito escalas para mensurar os estilos básicos da personalidade foram reduzidos, de modo que foram eliminados sinônimos, foi maximizada a representatividade dos itens e foi utilizado o critério de aproximadamente 20 itens por escala. Por fim, um total de 153 itens foi mantido, que compõem o atual PACL (Strack, 1987; Tous, Pont \& Muiños, 2006).

O estágio final para o desenvolvimento do instrumento referiu-se à verificação das propriedades psicométricas do PACL, fidedignidade e validade. Para o estudo da fidedignidade, foram recrutados 400 participantes adultos. Foram calculados os coeficientes alfa de Cronbach e realizado o teste-reteste para um mês, dois meses e três meses. Os coeficientes alfa variaram entre 0,65 e 0,89 , e no teste-reteste variaram entre 0,55 e 0,90 para um mês, 0,63 e 0,89 para dois meses, e 0,63 e 0,85 para três meses.

Para o estudo de validade, foram recrutados mais de 1.000 participantes, de ambos os sexos, entre 17 e 64 anos de idade. O PACL foi correlacionado com sete diferentes instrumentos. Segundo Strack (1987), as análises realizadas com o instrumento apontaram boa adequação de sua estrutura interna, estabilidade temporal e validade, de modo que as escalas parecem corresponder ao modelo teórico proposto por Millon (Millon \& Davis, 1996).

Portanto, a versão final do PACL pode ser considerada como um check-list adequado para mensurar os oito modelos básicos da personalidade propostos por Millon (Millon \& Davis, 1996). Pode ser utilizada para avaliação de adultos saudáveis (população em geral) e com amostras clínicas, devido às altas correlações verificadas entre as escalas do PACL e o Millon Clinical Multiaxual Inventory (Guevara \& Strack, 1998; Millon \& Davis, 1996), este último um instrumento para avaliação de transtornos do eixo I e II do Manual Diagnóstico e Estatístico de Transtornos Mentais - DSM-IVTR (2003). Além das oito escalas para os modelos básicos, esse instrumento contém uma escala Indicadora de Problema (IP) que aponta para aspectos das três personalidades severas de Millon (esquizotípica, borderline e paranóide) e é uma indicadora de distúrbios na personalidade. Para responder o instrumento, o respondente deve avaliar quais adjetivos ele acredita ou não serem auto-descritivos (Guevara \& Strack, 1998; Strack \& Lorr, 1990).

Segundo Strack (1991), o PACLé caracterizado como um instrumento de avaliação de fácil compreensão e aplicação, diretamente baseado em uma sólida teoria da personalidade, útil como inventário de auto-relato e classificação, que possui propriedades psicométricas satisfatórias. Como pode ser observado na Tabela 1, cada estilo básico da personalidade avaliado pelo PACL apresenta um correspondente patológico.

\section{As Escalas do PACL}

A seguir são apresentadas as descrições das nove diferentes escalas que compõem o PACL, a partir do que é descrito por Strack (1991). Essas escalas refletem os oito estilos básicos da personalidade, segundo a proposta de Millon (Millon \& Davis, 1996), de modo a fornecerem vários aspectos das personalidades não-patológicas. E, ainda, há uma nona escala que se refere a estilos mais severos da personalidade. Cabe ressaltar que essas descrições são de casos prototípicos, isto é, casos de pessoas com todas as principais características do estilo salientes (Millon \& Davis, 1996). Isso faz com que as descrições pareçam um tanto artificiais pois, de fato, casos reais são sempre menos extremados do que as descrições prototípicas. Optou-se por apresentar dessa forma para facilitar a compreensão das características do estilo. Entretanto, deve-se ter em mente que os casos terão algumas características, mas não outras, o que inclui também combinações de diferentes estilos da personalidade.

A primeira escala representa o Estilo Introvertido, caracterizado por pessoas distantes, solitárias e introvertidas que usualmente preferem envolvimentos superficiais com os outros e demonstram pouco interesse para atividades sociais, nas quais não se sentem gratificadas. São vistas pelos outros como indiferentes e despreocupadas, e normalmente são julgadas como preguiçosas, quietas e 
Tabela 1. Escalas e estilos básicos da personalidade (a partir de Strack, 1991, 2005).

\begin{tabular}{|c|c|c|c|c|}
\hline $\begin{array}{l}\text { Escalas PACL/ } \\
\text { Estilos Básicos de } \\
\text { Personalidade }\end{array}$ & $\begin{array}{l}\text { Transtorno da } \\
\text { Personalidade } \\
\text { Correspondente }\end{array}$ & $\begin{array}{c}\text { Orientações para Existência e Modos de } \\
\text { Adaptação }\end{array}$ & $\begin{array}{l}\text { Número de } \\
\text { Itens das } \\
\text { Escalas }\end{array}$ & $\begin{array}{l}\text { Exemplo de Item } \\
\text { das Escalas }\end{array}$ \\
\hline Introvertido & Esquizóide & $\begin{array}{l}\text { Desapego (redução nos ganhos e } \\
\text { satisfação); passivo }\end{array}$ & 19 & Isolado, distante, reservado \\
\hline Inibido & Evitativo & $\begin{array}{l}\text { Desapego (redução nos ganhos e } \\
\text { satisfação); ativo }\end{array}$ & 27 & Excluído, tímido, acanhado \\
\hline Cooperativo & Dependente & $\begin{array}{c}\text { Dependente (avaliação da própria } \\
\text { satisfação a partir dos outros); passivo }\end{array}$ & 26 & Amável, dócil, inocente \\
\hline Sociável & Histriônico & $\begin{array}{c}\text { Dependente (avaliação da própria } \\
\text { satisfação a partir dos outros); ativo }\end{array}$ & 21 & $\begin{array}{l}\text { Divertido, falante, } \\
\text { dramático }\end{array}$ \\
\hline Confiante & Narcisista & Independente (confiança no eu); passivo & 22 & $\begin{array}{l}\text { Egoísta, convencido, } \\
\text { vaidoso }\end{array}$ \\
\hline Enérgico & Anti-social & $\begin{array}{l}\text { Independente (não considera o mundo ao } \\
\text { redor nas decisões); ativo }\end{array}$ & 26 & $\begin{array}{l}\text { Autoritário, competitivo, } \\
\text { ofensivo }\end{array}$ \\
\hline Respeitoso & Compulsivo & $\begin{array}{l}\text { Ambivalente (conflitos entre seguir } \\
\text { os próprios desejos e valores ou dos } \\
\text { outros); passivo }\end{array}$ & 21 & $\begin{array}{l}\text { Moralista, íntegro, } \\
\text { disciplinado }\end{array}$ \\
\hline Sensível & Negativista & $\begin{array}{l}\text { Ambivalente (conflitos entre seguir } \\
\text { os próprios desejos e valores ou dos } \\
\text { outros); ativo }\end{array}$ & 26 & $\begin{array}{l}\text { Aborrecido, irritado, } \\
\text { temperamental }\end{array}$ \\
\hline $\begin{array}{l}\text { Indicadora de } \\
\text { Problema }\end{array}$ & & & 11 & $\begin{array}{c}\text { Desesperado, } \\
\text { desestruturado, abatido }\end{array}$ \\
\hline
\end{tabular}

reservadas. Frequentemente, ficam como pano de fundo da vida social e trabalham de maneira silenciosa, sem que sejam percebidas. Costumam realizar as tarefas por si sós, são tipicamente confiáveis e leais, não são exigentes, e raramente se aborrecem com barulhos ou perturbações ao redor. $\mathrm{O}$ estilo Introvertido pode ser visto como equilibrado e calmo, entretanto, também pode ser percebido como alheio ou insensível aos sentimentos e pensamentos dos outros. Tais características podem ser interpretadas como sinais de indiferença ou rejeição, e revelam uma dificuldade sincera em conseguir perceber o humor e desejos alheios. A personalidade Introvertida pode ser lenta e metódica em sua conduta, pouco espontânea e ressonante, e ser desajeitada ou tímida em situações sociais ou de grupos. Muitas vezes se vêem como pessoas simples e não sofisticadas, e são usualmente modestas em avaliar suas próprias habilidades. Ao mesmo tempo, a atitude plácida e a habilidade para superar altos e baixos sem se desordenar são traços frequentemente valorizados pelas pessoas ao redor.

A Escala 2, correspondente ao Estilo Inibido, também é marcada por uma tendência para o afastamento social. Entretanto, para indivíduos Inibidos, esse funcionamento é motivado não pelo desinteresse, mas por um medo de possíveis consequências negativas. Pessoas Inibidas tendem a ser sensíveis aos próprios sentimentos e aos dos outros. Elas frequentemente antecipam que os outros serão críticos ou irão rejeitá-las, e, por conta disso, frequentemente se envergonham ou ficam nervosas em ambientes não familiares. Nesse sentido, membros da família e conhecidos podem vê-las como pessoas desnecessariamente nervosas, desconfiadas e temerosas. Embora indivíduos Inibidos tendam a se entender bem com os outros, apresentam dificuldades em se relacionar em nível pessoal. Usualmente desejam ficar à vontade frente aos outros e costumam desejar proximidade, mas são frequentemente incertos das consequências da proximidade e intimidade para que consigam baixar a guarda. Como resultado, experimentam sentimentos de solidão, mas são incapazes de, ou se negam a, fazer algo sobre isso. Por conta da sensibilidade para com os outros, pessoas Inibidas são frequentemente descritas como afáveis, atenciosas e empáticas a conhecidos próximos. Frequentemente, preferem trabalhar sozinhas ou em pequenos grupos com pessoas que possam vir a conhecê-las bem. Fazem o melhor em um ambiente de trabalho estável onde a estimulação e a perturbação são mantidas em um nível baixo ou moderado. Pessoas que trabalham com tipos Inibidos precisam apreciar sua sensibilidade com feedback positivo e negativo, assim como a necessidade de desenvolver confiança em um período longo de tempo. 
A terceira escala diz respeito ao Estilo Cooperativo, caracterizado por pessoas que podem ser identificadas por uma necessidade de aprovação e afeição, e por uma disposição em viver de acordo com os desejos alheios. Elas usualmente adaptam seus comportamentos aos padrões dos outros, e no processo podem negar suas próximas necessidades. Interpessoalmente, esses indivíduos são frequentemente cooperativos, confiáveis, atenciosos e respeitadores aos outros. Podem parecer calmos, dóceis, modestos, agradáveis ou ingênuos. Indivíduos Cooperativos costumam perceber a si próprios como modestamente favorecidos em termos de suas habilidades. Normalmente ficam satisfeitos quando podem contar com outros, mas podem se sentir inseguros quando são deixados por si próprios. Especialmente quando encaram dificuldades ou situações de estresse, pessoas Cooperativas procuram outros para fornecer autoridade, liderança e direção. Frequentemente, preferem trabalhar em grupo e tipicamente se sobressaem em termos de suporte e direção. Eles são usualmente concordantes em seguir direções e cooperar com co-trabalhadores em trabalhos em equipe.

O Estilo Sociável, correspondente à quarta escala, similarmente ao que ocorre com a personalidade Cooperativa, apresenta uma necessidade de atenção e aprovação. Entretanto, diferente do estilo Cooperativo, o tipo Sociável toma iniciativa em assegurar seus reforçamentos para ser o centro das atenções. É caracterizado por um estilo expansivo, falador e extrovertido, e tende a ser cheio de vida (vigoroso), surpreendente e exuberante. Essas pessoas são tipicamente vistas pelos outros como espontâneas, espertas, entusiásticas e vigorosas. Podem ser sensíveis às necessidades e aos desejos alheios, ao menos com relação a aspectos que os ajudem a conseguir a atenção que procuram. Indivíduos sociáveis também podem ser vistos como instáveis em seus relacionamentos. Podem ter rápidas mudanças de humor e emoções, e isso pode aparecer através de uma superficialidade e inautenticidade nos relacionamentos. Essas pessoas tendem a preferir novidades e excitação, e ficam aborrecidas com atividades ordinárias e mundanas. Como a personalidade Cooperativa, indivíduos Sociáveis parecem desconfortáveis ou desanimados quando deixadas por si sós. Não surpreendentemente, tipos Sociáveis frequentemente se sobressaem em trabalhos de grupo, quando podem exercer seu estilo exuberante. Eles frequentemente interagem bem com o público, podem ser habilidosos e adeptos a animar e motivar os outros, e usualmente irão fazer seu melhor mesmo em circunstâncias difíceis.

A quinta escala, o Estilo Confiante, se caracteriza por indivíduos distantes, calmos, confiantes, com tendência ao egocentrismo e à autoconfiança. Esses indivíduos podem ter um senso apurado de sua própria importância, exclusividade ou merecimento. Pessoas Confiantes apreciam a atenção dos outros e podem ser socialmente ousados, embora sejam raramente chamativos. Podem ser demasiadamente egoístas e ficar tão preocupados com si próprios que demonstram uma carência de empatia e atenção para com os outros. Essas pessoas têm uma tendência a acreditar que os outros compartilham, ou poderiam compartilhar, seu senso de importância. Como resultado, podem esperar que os outros se submetam a seus desejos e necessidades, e os atendam. Ironicamente, a aparente segurança dos indivíduos Confiantes pode cobrir sentimentos de inadequação pessoal e uma sensibilidade a críticas e rejeição. Desafortunadamente, eles normalmente não permitem que os outros vejam seu lado vulnerável. Quando o sentimento é exposto ou questionado, esses indivíduos são frequentemente desdenhosos, perturbadores ou vingativos. No local de trabalho, pessoas Confiantes gostam de se encarregar de maneira empática, frequentemente possibilitando que os outros confiem neles. Sua auto-segurança, sutileza e sedução frequentemente ganham sua posição supervisora e de liderança.

O Estilo Enérgico, que representa a sexta escala, de maneira semelhante ao estilo Confiante, se refere a indivíduos que podem ser identificados por uma inclinação a virar para si como fonte primária de gratificação. Entretanto, enquanto a personalidade Confiante internaliza um senso de auto-importância, pessoas Enérgicas se vêem como guiadas a provar seus próprios méritos. São caracterizadas por um estilo pessoal de assertividade, dominação e determinação. Tendem a ser teimosas, ambiciosas, competitivas e autodeterminadas. Podem perceber o mundo como um local rude onde a agressividade é necessária para assegurar o sucesso, e, portanto, indivíduos Enérgicos são frequentemente grosseiros e insensíveis em dialogar com os outros. Em contraste, exteriormente a aparência poderosa, esses indivíduos podem sentir uma insegurança interna e ter medo de baixar a guarda. No local de trabalho, essa personalidade é frequentemente guiada a se sobressair. Os indivíduos trabalham duro para conseguir seus objetivos, são competitivos, e dão seu melhor em locais onde podem tomar controle ou trabalhar de maneira independente. Em posições de supervisão ou liderança essas pessoas usualmente encarregam-se de fazer os trabalhos. Entretanto, frequentemente necessitam moderar uma inclinação a demandar dos outros o que demandam de si próprios.

A sétima escala, o Estilo Respeitoso, representa indivíduos responsáveis, habilidosos e respeitosos da autoridade, com tendência ao conformismo e a trabalhar severamente para apoiar regras e regulamentos. Apresentam uma necessidade de ordem e são tipicamente convencionais em seus interesses. Essas pessoas podem ser demasiadamente obedientes a regras, assim como perfeccionistas, inflexíveis e críticas. Um estilo interpessoal formal e uma notável constrição de afeto podem fazer algumas pessoas Respeitosas serem vistas como frias, distantes e contidas. Debaixo de sua propriedade social há frequentemente um medo de desaprovação e rejeição, ou um senso de culpa em cima de faltas percebidas. Indecisão e inabilidade a encarregar-se podem ser evidentes em algumas dessas pessoas devido a um medo de estarem errados. Entretanto, entre co-trabalhadores e amigos, personalidades Respeitosas são mais conhecidas por serem organizadas, confiáveis e diligentes. Demonstram um forte senso de responsabilidade e lealdade, são cooperativos em esforços de grupo, mostram persistência até mesmo em circunstâncias difíceis e trabalham bem sob supervisão.

A penúltima escala, Estilo Sensível, representa indivíduos que tendem a ser incomuns e únicos em suas respostas ao mundo. Costumam marcar o mundo com uma batida própria e são frequentemente infelizes com status quo. Podem ser rápidos a desafiar regras ou autoridades que considerem arbitrárias ou injustas, assim como guardar ressentimento 
sem expressar isso diretamente, de modo a reverter suas reações a um comportamento passivo-agressivo para fazer seus sentimentos conhecidos. Muitas pessoas Sensíveis se sentem não ajustadas e se vêem interpessoalmente pouco habilidosas. De fato, aos outros, frequentemente parecem estranhas, nervosas ou confusas, e parecem estar com raiva ou insatisfeitas com si próprias e o mundo. Podem ser indecisas e ter humores e interesses flutuantes. Um ar de incerteza e insatisfação geral pode refletir uma dependência e senso de inadequação pessoal. Em suas melhores qualidades, pessoas Sensíveis podem ser espontâneas, criativas e desejosas de falar sobre o que acreditam. Essas qualidades fazem com que sejam especialmente adaptadas a trabalhos que não tenham regras inflexíveis, que lhes dêem certa independência para supervisão e que requeiram obrigações incomuns e expressão criativa.

Por fim, a nona escala, Indicadora de Problema, é composta por itens que avaliavam as personalidades Esquizotípica, Borderline e Paranóide. Apesar da escala não definir um estilo da personalidade, altos escores são indicativos de problemas importantes na personalidade, com potencial a transtornos. Sujeitos com altos escores possuem traços de transtornos da personalidade e sintomas como fraqueza egóica e instabilidade afetiva. São propensos a parecerem ansiosos, disfóricos e temerosos, exibem grande autodúvida, e expressam insatisfação com si e com outros. Podem ter longos problemas de ajustamento em áreas da vida como o trabalho, a escola e relacionamentos. Aqueles que têm pontuação alta nessa escala não se enquadram na mesma figura que aqueles que têm uma baixa pontuação, mas avaliações adicionais são recomendadas antes de se chegar a conclusões acerca da presença de transtornos nesses indivíduos.

\section{Estudos com o PACL}

Além dos estudos de validade e precisão realizados com o PACL durante o desenvolvimento do instrumento, diversos estudos têm sido empregados para verificar as propriedades psicométricas, eficiência do instrumento em diferentes amostras e a correlação entre o PACL e outros testes para avaliação da personalidade (Strack \& Lorr, 1990). Um estudo realizado por Guevara e Strack (1998) tinha como objetivo verificar evidências de validade do Millon Index of Personality Styles (MIPS), um instrumento para avaliação da personalidade saudável baseado na teoria da personalidade de Millon. Para tanto, foram verificadas as correlações entre as escalas do MIPS e as escalas do PACL. Segundo os autores do estudo, as associações moderadamente altas, que variaram de 0,43 à 0,71 para as correlações previamente esperadas, encontradas entre o PACL e o MIPS, sinalizam que os estilos básicos da personalidade propostos por Millon estão de acordo com estilos da personalidade propostos posteriormente em sua teoria.

Tous e cols. (2006) realizaram um estudo que tinha como objetivo verificar a eficácia do PACL em uma amostra de adolescentes. O instrumento foi aplicado em 2.250 adolescentes, a partir de uma versão em espanhol do PACL. A partir da análise fatorial, foram encontrados 44 fatores distintos que explicavam 58,2\% da variância total. Segundos os autores, a técnica do scree test identificou um máximo de cinco fatores independentes na análise. Dos fatores encontrados, quatro coincidiram com os fatores encontrados em um estudo realizado por Strack e Lorr (1990) em uma amostra de adultos. Ainda, a partir da escala Indicadora de Problema, os autores do estudo sugeriram que o PACL é um instrumento útil na prevenção de transtornos da personalidade em adolescentes.

Por fim, o estudo realizado por Strack e Lorr (1990) empregou a análise fatorial com os itens do PACL. Foram encontrados 34 fatores que explicavam 49,5\% da variância total. A partir do scree plot identificou-se um máximo de cinco fatores independentes na análise. Os autores do estudo apontam que os fatores encontrados do PACL podem ser comparados com os fatores encontrados em análises com o Millon Clinical Multiaxial Inventory (MCMI), um instrumento para avaliação de transtornos da personalidade segundo a proposta teórica de Millon. Tal similaridade entre os fatores desses instrumentos sugere que, de fato, a personalidade saudável e patológica podem ser entendidas em um continuum.

Pode-se observar que o PACL é um instrumento para avaliação da personalidade que apresenta propriedades psicométricas satisfatórias em estudos distintos. Ressalta-se também que entre as teorias da personalidade frequentemente citadas na literatura, é provável que o único modelo teórico que se propõe a integrar teoria, avaliação e intervenção dos estilos da personalidade seja o modelo proposto por Millon (Millon \& Davis, 1996; Strack \& Millon, 2007), no qual o PACL está baseado. Pela contribuição teórica e prática de seu modelo para o estudo, avaliação e intervenção na área da personalidade e seus transtornos, em 2003, Millon recebeu da American Psychological Association (APA) um prêmio intitulado "Award for Distinguished Professional Contributions to Applied Research".

Portanto, dada a robustez do modelo teórico de Millon, a importância da avaliação da personalidade saudável e as qualidades psicométricas verificadas no PACL, este estudo teve como objetivo produzir uma versão brasileira do PACL, assim como verificar evidências de validade da estrutura interna do instrumento (análise fatorial), adequação dos itens e evidências de validade por meio da relação com variáveis externas, e investigar a consistência interna do instrumento. Esperavase, assim, encontrar resultados similares aos de Strack (1987, 1991), com relação aos estudos de validade e fidedignidade do instrumento, e aos de Strack e Lorr (1990), no que diz respeito ao número e composição dos fatores do instrumento.

\section{Método}

\section{Participantes}

Participaram do presente estudo 203 universitários dos cursos de Administração ( $\mathrm{N}=51)$, Ciências da Computação $(\mathrm{N}=50)$, Engenharia da Computação $(\mathrm{N}=25)$ e Psicologia $(\mathrm{N}=77)$, de ambos os sexos $(51,7 \%$ do sexo feminino e $48,3 \%$ do sexo masculino), entre 18 e 50 anos de idade $(\mathrm{M}=25$ anos; $\mathrm{DP}=6,1)$. 


\section{Materiais e Procedimentos}

Foram aplicados dois instrumentos: o PACL (Strack, $1987,1991)$ que foi traduzido e adaptado segundo as recomendações de Beaton, Bombardier, Guillemin e Ferraz (2000), respondido pela amostra como um todo, e o Inventário dos 16 Fatores de Personalidade (16PF - 5 ed.; Cattell \& Cattell, 1993; Cattell, Cattel \& Cattel, 1993), respondido por 25 participantes da amostra total. A versão traduzida e adaptada do PACL é composta por 256 adjetivos, para os quais os participantes deveriam assinalar "sim", "não" ou “?" (que correspondeu a "não sei"), como resposta à questão inicial (destacada nas instruções do instrumento): "Você se considera uma pessoa...".

O 16PF é um instrumento composto por 185 itens distribuídos em 16 escalas (bipolares) distintas: Expansividade (A), Inteligência (B), Estabilidade Emocional (C), Afirmação (E), Preocupação (F), Consciência (F), Desenvoltura (H), Brandura (I), Confiança (L), Imaginação (M), Requinte (N), Apreensão (O), Abertura a Novas Experiências (Q1), Auto-Suficiência (Q2), Disciplina (Q3) e Tensão (Q4). Na combinação entre os 16 fatores, obtêm-se os cinco fatores globais: extroversão, ansiedade, rigidez de pensamento, independência e auto-controle. O instrumento é composto de um caderno de perguntas e uma folha de respostas, em que o participante deverá fazer a opção que melhor o descreva, sendo verdadeiro, falso ou ponto de interrogação, quando as outras opções não forem adequadas, e transcrever na folha de respostas.

Para o presente estudo foi utilizada, inicialmente, uma versão traduzida e adaptada do PACL por Primi e cols. (2002). A primeira fase do trabalho consistiu na solicitação do back-translation por um nativo da língua de origem do instrumento (inglês), de modo que foram descartados os adjetivos que não eram correspondentes aos itens da versão original do instrumento. A partir do back-translation, foi desenvolvida uma lista composta por 256 adjetivos (todos com base nos adjetivos do PACL).

A coleta de dados foi realizada em salas de aula e foi entregue o Termo de Consentimento Livre Esclarecido aos participantes dos diferentes cursos. Assim, uma vez lido e concordado pelo participante, este poderia participar da pesquisa. A participação na pesquisa consistiu em responder a versão brasileira do PACL $(\mathrm{N}=203)$ e o $16 \mathrm{PF}(\mathrm{N}=25)$.

Para análise dos resultados, primeiramente foi utilizado o software MicroFact (Assessment Systems Corporation, 1996), que possibilita a realização da análise fatorial de matrizes de correlação tetracórica de maneira adequada (Primi \& Almeida, 1998). Posteriormente, foi utilizado o software SPSS, que é um dos instrumentos mais utilizados para verificação da análise fatorial de escalas em instrumentos de avaliação psicológica (Artes, 1998).

\section{Resultados e Discussão}

\section{Análise descritiva dos itens}

Primeiramente, buscou-se identificar quais dos 256 adjetivos apresentavam baixa variabilidade como descritores da personalidade na amostra estudada, isto é, aqueles adjetivos que eram excessivamente escolhidos (resposta "sim") ou preteridos ("não"). Considerou-se como sendo de baixa variabilidade um item com mais de $80 \%$ de "sim" ou de "não" pelos participantes. Também foram identificados adjetivos para os quais o grupo apresentou dificuldade de compreensão, aqueles cuja alternativa "?" (correspondente a não saber o significado) foi escolhida por mais de $10 \%$ da amostra. Assim, foram eliminados 50 adjetivos por apresentarem baixa variabilidade, como, por exemplo, "justo", "simpático", "limpo", "honesto", "desinteressado" e "inútill". Foram também eliminados 25 itens por apresentarem dificuldades em sua compreensão, como, por exemplo, "austero", "combativo", e "gregário".

\section{Análise fatorial dos itens}

Os 181 adjetivos mantidos no instrumento foram submetidos à análise fatorial, empregando-se o software MicroFact, que efetua adequadamente a análise fatorial de matrizes de correlação tretacóricas (Primi \& Almeida, 1998). A decisão do número de fatores a serem extraídos, a partir da rotação Varimax, foi tomada com base no scree test, que indicou uma solução com cinco fatores (F1 a F5) como a mais adequada, que explicaram, respectivamente, $16,1 \%, 13,3 \%, 13,6 \%$, $11,5 \%$ e $11,2 \%$ da variabilidade. Na Tabela 2 são apresentados o número de itens por fator e as cargas fatoriais mínimas e máximas de cada um deles.

De acordo com a Tabela 2, observa-se que o número de itens dos fatores variou entre 29 e 46, e a média das cargas fatoriais variou de 0,446 e 0,477 . Os itens agrupados na dimensão do pólo positivo do Fator 1 (F1) correspondem aos adjetivos das escalas Introvertido e Inibido do instrumento original, e no pólo negativo, adjetivos da escala Sociável. O Fator 2 (F2) apresenta adjetivos das escalas originais Sensitivo e Inibido. No pólo negativo do Fator 3 (F3) são encontrados adjetivos das escalas Respeitoso e Cooperativo, e, no pólo positivo, itens da escala Confiante. O Fator 4 (F4) reuniu, no pólo positivo, adjetivos das escalas originais Sensitivo, Inibido e Cooperativo, e no pólo negativo, adjetivos da escala Enérgico. Por fim, o Fator 5 (F5) apresenta adjetivos das escalas originais Sociável, Confiante e Enérgico no pólo positivo, e Inibido no pólo negativo.

Strack e Lorr (1990), em estudo semelhante, encontraram cinco fatores, dos quais três agruparam adjetivos de duas escalas do PACL. O Fator 1 agrupou adjetivos das escalas Energético e Confiante, o Fator 2 das escalas Inibido e Sensitivo, o Fator 3 da escala Respeitoso, o Fator 4 das escalas Introvertido e Inibido, e o Fator 5 da escala Sociável. Desse modo, observa-se algumas semelhanças entre os resultados aqui encontrados e os do estudo de Strack e Lorr (1990), detalhadas na Tabela 3 .

Como pode ser observado, os Fatores 1 e 2 são similares aos Fatores 2 e 4 do estudo de Strack e Lorr (1990), porém, os outros fatores apresentaram uma correspondência menor com os dados obtidos no estudo citado. É importante ressaltar que não foi encontrado nenhum fator no qual os adjetivos da escala Confiante tenham aparecido claramente.

Dadas as variações, de um modo geral, a versão brasileira organizou-se de forma semelhante à versão original. Entretanto, deve-se levar em conta que, para este estudo, o número 
Tabela 2. Solução de fatores e cargas fatoriais.

\begin{tabular}{|c|c|c|c|c|}
\hline Escalas & Número de itens & $\begin{array}{c}\text { Cargas Fatoriais } \\
\text { Máximas }\end{array}$ & $\begin{array}{c}\text { Cargas Fatoriais } \\
\text { Mínimas }\end{array}$ & Média das Cargas Fatoriais \\
\hline Fator 1 & 46 & 0,677 & 0,253 & 0,462 \\
\hline Fator 2 & 36 & 0,709 & 0,244 & 0,477 \\
\hline Fator 3 & 41 & 0,677 & 0,175 & 0,459 \\
\hline Fator 4 & 29 & 0,758 & 0,234 & 0,449 \\
\hline Fator 5 & 29 & 0,733 & 0,190 & 0,446 \\
\hline
\end{tabular}

Tabela 3. Comparação da solução fatorial deste estudo com a obtida por Strack e Lorr (1990).

\begin{tabular}{lll}
\hline \multicolumn{1}{c}{ Pólo +} & \multicolumn{1}{c}{ Pólo - } & Strack e Lorr (1990) \\
\hline (F1) Introvertido e Inibido & Sociável & (Fator 1) Introvertido e Inibido \\
(F2) Sensitivo e Inibido & --- & (Fator 2) Sensitivo e Inibido \\
(F3) Confiante & Respeitoso e Cooperativo & (Fator 3) Respeitoso \\
(F4) Sensitivo & Energético & (Fator 4) Introvertido \\
(F5) Sociável, Confiante e Energético & Inibido & (Fator 5) Sociável \\
\hline
\end{tabular}

de participantes foi muito menor que o número apresentado por Strack e Lorr (1990) e, ainda, foram utilizadas metodologias distintas para realização da análise fatorial em cada um dos estudos. Tais diferenças podem explicar algumas diferenças dos resultados. Apesar disso, é possível verificar um razoável grau de correspondência na estrutura fatorial na versão brasileira.

\section{Consistência interna das escalas}

Foram verificadas evidências de consistência interna a partir da reorganização dos itens da versão brasileira do PACL de modo a compor as oito escalas de estilos da personalidade do PACL original (Strack, 1991). A partir disso, cada escala foi composta pelos itens que melhor representassem o construto subjacente a elas. Para tanto, foi utilizada a matriz de cargas fatoriais, sendo os itens ordenados em função da escala de que faziam parte no original americano. Era esperado que os adjetivos de cada uma das escalas fossem claramente discriminados somente em um ou dois dos fatores, caracterizando um contraste entre as escalas. Tal padrão foi observado para os adjetivos das escalas Cooperativo, Inibido, Introvertido, Respeitoso e Sensitivo. As escalas Enérgico, Confiante e Sociável apresentaram um padrão mais complexo, já que seus adjetivos aparecem com cargas dispersas nos cinco fatores.

Cada uma das escalas foi submetida a uma análise de consistência interna. Examinando as correlações item-total, alguns itens foram eliminados, chegando-se à versão final da versão brasileira do instrumento. É importante ressaltar que, com a exclusão de determinados itens, de acordo com os critérios estatísticos citados anteriormente, a nona escala, Indicadora de Problema (Strack, 1987), não pôde ser retratada na versão brasileira do PACL.

$\mathrm{Na}$ Tabela 4 são apresentadas as estatísticas descritivas das escalas e os coeficientes de consistência interna (coeficiente alfa), assim como os dados obtidos com a versão original do PACL. Como pode ser observado, os valores da versão brasileira são similares aos obtidos na versão norteamericana, e, de fato, algumas escalas da versão traduzida apresentaram resultados mais adequados do que a versão original do instrumento. De modo geral, os valores da versão traduzida variaram entre moderados e altos. É importante ressaltar, também, que as escalas variaram em termos de aquiescência (propensão a evocar respostas "sim"), formando dois extremos: de um lado, as escalas Confiante e Introvertido, e, de outro, Respeitoso e Cooperativo.

\section{Análise fatorial das escalas}

A partir das oito escalas da versão brasileira do PACL, efetuou-se uma análise fatorial, com rotação Varimax, visando verificar a estrutura de segunda ordem do instrumento. Essa análise, realizada com uso do software SPSS, resultou em três fatores, como apresentado na Tabela 5.

Como pode ser observado, os três fatores obtidos representam, respectivamente, as escalas Introvertido, Inibido e Sensível (Fator 1), Sociável, Confiante e Energético (Fator 2), e Cooperativo e Respeitoso (Fator 3). Essa organização assemelha-se, em parte, ao agrupamento dos transtornos de personalidade do Eixo II do DSM-IV- 
Tabela 4. Estatísticas descritivas e consistência interna das escalas.

\begin{tabular}{lcccccccccccc}
\hline Escalas & $\mathrm{N}$ & $\mathrm{N}^{\mathrm{o}}$ itens BR & Alfa BR & $\mathrm{N}^{\mathrm{o}}$ itens EUA & Alfa EUA & Min & Max & M & DP & Assim. & Curt. \\
\hline Introvertido & 202 & 16 & 0,84 & 16 & 0,77 & 0,00 & 0,88 & 0,21 & 0,19 & 1,36 & 1,56 \\
Inibido & 203 & 32 & 0,95 & 21 & 0,87 & 0,00 & 1,00 & 0,30 & 0,19 & 1,09 & 1,18 \\
Cooperativo & 199 & 16 & 0,67 & 18 & 0,81 & 0,06 & 1,00 & 0,69 & 0,18 & $-0,99$ & 0,95 \\
Sociável & 203 & 20 & 0,66 & 19 & 0,84 & 0,15 & 1,00 & 0,58 & 0,18 & $-0,16$ & $-0,38$ \\
Confiante & 200 & 8 & 0,67 & 15 & 0,81 & 0,00 & 0,88 & 0,19 & 0,19 & 1,25 & 1,44 \\
Energético & 201 & 19 & 0,76 & 21 & 0,85 & 0,05 & 0,95 & 0,44 & 0,17 & 0,32 & 0,05 \\
Respeitoso & 202 & 22 & 0,88 & 20 & 0,82 & 0,05 & 1,00 & 0,74 & 0,18 & $-1,28$ & 2,30 \\
Sensível & 203 & 25 & 0,90 & 17 & 0,70 & 0,00 & 0,96 & 0,32 & 0,22 & 0,51 & $-0,48$ \\
\hline
\end{tabular}

Nota: N: Número de participantes; Min: Mínimo; Max: Máximo; M: Média; DP: Desvio Padrão; Assim: Assimetria; Curt: Curtose.

TR (2003): Grupo A (esquisito-excêntrico), representado pelos transtornos paranóide, esquizóide e esquizotípico; Grupo B (dramático-emotivo), composto pelos transtornos anti-social, borderline, histriônico e narcisista; e Grupo C (ansioso-medroso), representado pelos transtornos evitativo, dependente e compulsivo.

Os dados aqui evidenciados, no que diz respeito aos três fatores encontrados, apresentaram algumas semelhanças e algumas diferenças com os resultados obtidos por Strack (1991) a partir do PACL norte-americano. Em seu estudo, Strack obteve três fatores: o primeiro composto pelas escalas Inibido e Sensível (pólo positivo) e Respeitoso (pólo negativo), o segundo pelas escalas Confiante e Energético (pólo positivo) e Cooperativo e Inibido (pólo negativo), e o terceiro pelas escalas Sociável (pólo positivo) e Introvertido (pólo negativo).

\section{Evidências de validade - correlações do PACL com o 16PF}

Dos 203 participantes deste estudo, 25 responderam também ao 16PF. Na Tabela 6 são apresentadas as correlações entre as escalas do PACL e as escalas do 16PF. A partir da análise das correlações significativas encontradas $(p<0,05)$, observa-se que a escala Introvertido correlacionou-se com o fator $\mathrm{L}+$, indicando desconfiança e cautela, e com o fator global ansiedade (FII). As escalas Inibido e Sensível (PACL) correlacionaram-se com os mesmos fatores $\mathrm{L}+\mathrm{e}$ ansiedade (FII), e com A-, o que sinaliza introversão (também com o fator global extroversão, FI-), Q2+, indicando tendência a ser solitário, individualista, e Q4+, indicando alto nível de tensão. Os dados obtidos parecem demonstrar convergência entre as escalas do PACL e 16PF, embora não se assemelhem aos resultados encontrados por Strack (1991).

A escala Cooperativo correlacionou-se com o fator Q1+, indicando pessoas renovadoras e experimentadas, o que parece incongruente entre as escalas e com os resultados exibidos por Strack (1991). A escala Sociável correlacionou-se com o fator $\mathrm{E}+$, indicando atitudes mais afirmativas e dominantes, com o fator $\mathrm{F}+$, o que indica despreocupação e alegria, com o fator $\mathrm{H}+$, que é relacionado à desenvoltura e desibinição, e com o fator $\mathrm{N}-$, o que indica simplicidade e sinceridade. A escala Sociável correlacionou-se também com extroversão e sociabilidade $(\mathrm{FI}+)$ e independência $(\mathrm{FIV}+)$. Esses resultados parecem ser congruentes entre si e apresentam semelhança com os dados obtidos por Strack (1991).

A escala Confiante apresentou correlação significativa com a escala $\mathrm{L}+$, o que indica desconfiança em relação aos outros, e a escala Respeitoso correlacionou-se com o pólo oposto, L-, indicando propensão a confiar nas pessoas. Por fim, a escala Enérgico correlacionou-se com o fator $\mathrm{M}+$, que é indicativo de imaginação, e com o fator $\mathrm{O}+$, associado à apreensão e baixo autocontrole (FV-). Esses resultados também não coincidem com os relatados por Strack (1991).

Os resultados apresentados aqui, acerca das correlações entre o PACL e o 16PF, devem ser considerados com cautela, uma vez que a amostra foi composta por um número pequeno de participantes para a análise, o que pode limitar a generalização dos dados obtidos. Ainda, as incongruências encontradas entre os resultados obtidos neste estudo com os dados obtidos por Strack (1991) podem ter sofrido interferência de uma diferença entre instrumentos, já que, no estudo de Strack, foi utilizada uma versão anterior da versão presentemente utilizada do 16PF. Para estudos futuros, a amostra deve ser ampliada, objetivando verificar a consistência dos resultados aqui apresentados.

Tabela 5. Fatores obtidos a partir da análise fatorial de segunda ordem com as oito escalas.

\begin{tabular}{lccc}
\hline Escalas & Fator 1 & Fator 2 & Fator 3 \\
\hline Introvertido & $\mathbf{0 , 8 7 8}$ & $-0,018$ & $-0,074$ \\
Inibido & $\mathbf{0 , 9 3 5}$ & $-0,117$ & 0,014 \\
Cooperativo & 0,049 & $-0,171$ & $\mathbf{0 , 8 5 2}$ \\
Sociável & $-0,140$ & $\mathbf{0 , 8 0 4}$ & 0,146 \\
Confiante & 0,349 & $\mathbf{0 , 5 8 2}$ & $-0,316$ \\
Enérgico & 0,083 & $\mathbf{0 , 8 6 8}$ & 0,026 \\
Respeitoso & $-0,189$ & 0,287 & $\mathbf{0 , 7 7 0}$ \\
Sensível & $\mathbf{0 , 8 1 9}$ & 0,286 & $-0,124$ \\
\hline
\end{tabular}


Tabela 6. Correlações do PACL com o 16PF.

\begin{tabular}{|c|c|c|c|c|c|c|c|c|}
\hline & Introvert. & Inibido & Cooperat. & Sociável & Confiant. & Enérgico & Respeit. & Sensível \\
\hline AI & $-0,176$ & $-0,408(*)$ & 0,339 & $-0,078$ & $-0,199$ & $-0,495(*)$ & $-0,076$ & $-0,393$ \\
\hline AQ & 0,229 & $0,422(*)$ & $-0,017$ & 0,285 & 0,232 & 0,363 & 0,012 & 0,342 \\
\hline A & $-0,271$ & $-0,422(*)$ & 0,206 & 0,239 & $-0,299$ & 0,155 & 0,352 & $-0,463(*)$ \\
\hline B & $-0,109$ & 0,088 & 0,240 & 0,306 & 0,185 & 0,366 & 0,187 & 0,123 \\
\hline $\mathrm{C}$ & $-0,033$ & $-0,176$ & $-0,185$ & 0,204 & 0,084 & $-0,060$ & $-0,203$ & $-0,034$ \\
\hline E & $-0,005$ & 0,050 & $-0,205$ & $0,477(*)$ & 0,089 & 0,081 & $-0,057$ & 0,174 \\
\hline $\mathrm{F}$ & $-0,189$ & $-0,129$ & 0,033 & $0,662(* *)$ & 0,189 & 0,259 & $-0,024$ & 0,023 \\
\hline G & $-0,023$ & $-0,035$ & 0,111 & 0,004 & $-0,078$ & $-0,214$ & $-0,008$ & $-0,112$ \\
\hline $\mathrm{H}$ & $-0,069$ & $-0,200$ & 0,083 & 0,377 & 0,127 & $-0,033$ & $-0,103$ & $-0,002$ \\
\hline I & $-0,067$ & $-0,174$ & 0,005 & 0,083 & $-0,116$ & 0,034 & 0,215 & $-0,376$ \\
\hline $\mathrm{L}$ & $0,420(*)$ & $0,558(* *)$ & 0,000 & 0,228 & $0,446\left(^{*}\right)$ & 0,126 & $-0,414(*)$ & $0,462(*)$ \\
\hline M & 0,143 & 0,284 & 0,197 & 0,164 & 0,059 & $0,517(* *)$ & 0,238 & 0,291 \\
\hline $\mathrm{N}$ & 0,281 & 0,334 & $-0,132$ & $-0,434(*)$ & 0,073 & $-0,281$ & $-0,272$ & 0,277 \\
\hline $\mathrm{O}$ & 0,362 & 0,347 & $-0,058$ & $-0,125$ & 0,245 & 0,392 & 0,013 & 0,227 \\
\hline Q1 & $-0,260$ & $-0,236$ & $0,446(*)$ & 0,008 & $-0,263$ & $-0,032$ & 0,305 & $-0,239$ \\
\hline Q2 & 0,231 & $0,446(*)$ & $-0,016$ & $-0,113$ & 0,096 & 0,317 & $-0,053$ & $0,400(*)$ \\
\hline Q3 & 0,322 & 0,284 & $-0,333$ & 0,092 & 0,284 & $-0,030$ & $-0,323$ & 0,246 \\
\hline Q4 & 0,329 & 0,393 & $-0,376$ & 0,064 & 0,234 & 0,278 & $-0,176$ & 0,374 \\
\hline F-I & $-0,320$ & $-0,471(*)$ & 0,139 & $0,520(* *)$ & $-0,069$ & 0,088 & 0,180 & $-0,363$ \\
\hline F-II & $0,405(*)$ & $0,516(* *)$ & $-0,092$ & $-0,037$ & 0,287 & 0,322 & $-0,105$ & 0,379 \\
\hline F-III & 0,210 & 0,253 & $-0,357$ & $-0,151$ & 0,268 & $-0,177$ & $-0,439(*)$ & 0,374 \\
\hline F-IV & $-0,019$ & 0,010 & 0,051 & $0,468(*)$ & 0,107 & 0,056 & $-0,059$ & 0,128 \\
\hline F-V & 0,123 & 0,030 & $-0,163$ & $-0,215$ & $-0,001$ & $-0,400(*)$ & $-0,222$ & $-0,075$ \\
\hline
\end{tabular}

\section{Considerações Finais}

Este estudo teve como objetivo produzir uma versão brasileira do PACL, partindo da verificação de evidências de validade de conteúdo (estrutura fatorial) e da adequação dos itens a partir dos fatores da versão original e dos fatores encontrados na versão brasileira, para então buscar por evidências de validade de critério e consistência interna do instrumento. Os resultados obtidos sugerem que a versão brasileira do PACL avalia os oito estilos básicos da personalidade propostos por Millon (Millon \& Davis, 1996; Strack, 1987), assim como a versão original do instrumento. No que diz respeito à consistência interna do instrumento, que se manteve superior a $0,70 \mathrm{em}$ cinco das oito escalas, os dados encontrados corroboraram os resultados apresentados por Strack (1987, 1991), e por Strack e Lorr (1990), no que se refere ao número e composição dos fatores do instrumento. Contudo, a versão em português do PACL apresentou algumas limitações, como, por exemplo, a acentuada opção dos participantes por itens socialmente aceitáveis ou desejáveis, enviesando o estudo para o pólo positivo (socialmente esperado).
Alguns resultados encontrados neste estudo, entretanto, divergem dos resultados encontrados por Strack (1991; Strack \& Lorr, 1990). Essa divergência pode ser explicada, em parte, por uma diferenciação da versão do $16 \mathrm{PF}$ utilizada nesta pesquisa e na norte-americana e também pelo número pequeno de amostragem do presente estudo. Por fim, é necessário que outros estudos busquem evidências de validade e precisão, assim como repliquem os procedimentos para a verificação da estrutura fatorial aqui realizados, de modo a confirmar, ou não, os dados aqui apresentados. Nesse sentido, para além das propriedades psicométricas do instrumento, é importante verificar a utilidade clínica do PACL, investigando seu potencial para avaliação dos estilos da personalidade no âmbito quantitativo (nomotético) e qualitativo (idiográfico) (Tavares, 2003).

É necessário que sejam realizados outros estudos com o PACL brasileiro em novas amostragens, provindas de universos mais amplos e diversificados de participantes. Tal ampliação no estudo do instrumento, antes que este seja usado sistematicamente no contexto clínico, justifica-se na medida em que, na utilização em psicoterapia, deve-se considerar um universo maior de pessoas e, portanto, os estudos com o instrumento devem abarcar minimamente este universo. 


\section{Referências}

American Psychological Association. (2003). Manual Diagnóstico e Estatístico de Transtornos Mentais - DSM-IV-TR (4 ed.). Porto Alegre: Artmed.

Artes, R. (1998). Aspectos estatísticos da análise fatorial de escalas de avaliação. Revista de Psiquiatria Clínica, 25, 223-228.

Beaton D., Bombardier C., Guillemin F., \& Ferraz M. B. (2000). Recommendations for the cross-cultural adaptation of health status measures. Spine, 25, 3186-3191.

Cattell, R. B., \& Cattell, H. E. P. (1993). Personality structure and the New Fifth Edition of the 16PF. Educational and Psychological Measurement, 55, 926-937.

Cattell, R. B., Cattell, A. K. S., \& Cattell, H. E. P. (1993). Questionário 16PF (5 $5^{\mathrm{a}}$. ed.). Rio de Janeiro: CEPA.

Davis, R. D. (1999). Millon: Essentials of his science, theory, classification, assessment, and therapy. Journal of Personality Assessment, 72, 330-352.

Guevara, L. F., \& Strack, S. (1998). An examination of Millon's dimensional and stylistic descriptions of normal personality. Journal of Personality Assessment, 71, 337-348.

Millon, T., \& Davis, R. D. (1996). Disorders of personality: DSM-IV and beyond. New Jersey: Wiley.

Primi, R., \& Almeida, L. S. (1998). Considerações sobre a análise factorial de itens com resposta dicotômica. Psicologia: Teoria, Investigação e Prática, 3, 225-234.

Primi, R., Bighetti, C. A., Munhoz, A. M. H., Noronha, A. P., Polydoro, S. A. J., Nucci, E. P., \& Pelegrini, M. C. K. (2002). Personalidade, interesses e habilidades: um estudo correlacional. Avaliação Psicológica, 1, 61-72.
Strack, S. (1987). Development and validation of an Adjective Check List to assess the Millon personality types in normal population. Journal of Personality Assessment, 51, 572-587.

Strack, S. (1991). Manual for the Personality Adjective Check List (PACL) (Rev.). Pasadena: 21st Century Assessment.

Strack, S. (2005). Measuring normal personality in the Millon way. Em Strack, S. (Org.), Handbook of personology and psychopatholog (pp. 3-49). New Jersey: John Wiley \& Sons.

Strack, S., \& Lorr, M. (1990). Item factor structure of the Personality Adjective Check List (PACL). Journal of Personality Assessment, 55, 86-94.

Tavares, M. (2003). Validade clínica. Psico-USF (Itatiba), 8, 125-136.

Tous, J. M., Pont, N., \& Muinos, R. (2006). Factor structure of items from the Personality Adjective Check List in a sample of normal adolescents. The Spanish Journal of Psychology, 9, 228-233.

Recebido em 19.09.07

Primeira decisão editorial em 06.03.09

Versão final em 07.04.09

Aceito em 27.04.09 